\title{
Brucella spp. Lumazine synthase as a novel immunomodulator to produce egg yolk antibodies
}

\author{
Demian Bellido ${ }^{1}$, Pablo Chacana ${ }^{1}$, Marina Mozgovoj ${ }^{1}$, Diego Gonzalez ${ }^{1}$, Fernando Goldbaum ${ }^{2}$, \\ Andrés Wigdorovitz ${ }^{1}$, María José Dus Santos ${ }^{1}$ \\ ${ }^{1}$ Institute Instituto de Virología, INTA Castelar, Hurlingham, Argentina \\ ${ }^{2}$ Fundación Instituto Leloir, Buenos Aires, Argentina \\ Email: dbellido@cnia.inta.gov.ar
}

Received 12 October 2011; revised 22 November 2011; accepted 28 December 2011

\begin{abstract}
Lumazine synthase from Brucella spp. (BLS) is a highly immunogenic decameric protein. It has been previously described as a carrier of peptides or proteins to increase their immunogenicity in different animal species, but its activity has never been evaluated in chickens. In this work, the use of BLS to improve the antibody response against bovine rotavirus (BRV) VP8d protein in laying hens was assessed. VP8d is the inner domain of the VP8 spike protein which preserves the sialic acid binding activity and the neutralizing epitopes present in the viral protein. Hens were immunized three times with $2 \mu \mathrm{g}$ of VP8d alone or fused to BLS. Hens inoculated with BLSVP8d developed higher antibody titers (evaluated by ELISA and viral neutralization test) than hens immunized either with VP8d alone or the mixture of VP8d and BLS. Furthermore, IgY antibodies against BLSVP8d were able to fully protect mice against challenge with virulent $B R V$ in a dose-depent-manner. Overall, these results demonstrate that BLS is a potent immonumodulator that enhances the antibody response in hens, thus increasing the concentration of specific $\operatorname{IgY}$ in the egg yolk, one of the main issues to be adressed in order to improve the use of the IgY technology.
\end{abstract}

Keywords: BLS; VP8; Bovine Rotavirus; IgY

\section{INTRODUCTION}

Administration of specific antibodies for prophylaxis and therapy of human and animal diseases has been extensively used. Mammalian antibodies from rabbits, humans, mice or horses, among others, have been applied for cancer therapy, inactivation of toxic substances such as drugs or snake venoms and for the treatment of infectious diseases. In the last decades, there has been an increasing interest in the oral administration of specific antibodies for infections in the gastrointestinal tract [1].
This strategy has demonstrated to be successful in the treatment and prophylaxis of diseases caused by bacteria, viruses or even parasites [2]. However, large scale production of mammalian antibodies is expensive and uneasy. To overcome these difficulties, egg yolk antibodies are proposed as a low-cost and feasible alternative [3]. Since the early 1980's, egg yolk antibodies have been deeply studied $[4,5]$. IgY is the only immunoglobulin isotype present in the egg yolk, the main serum immunoglobulin in birds and it is considered to be ancestral of mammals IgG and IgE [4]. The use, production and purification of the egg yolk IgY is known as IgY technology [6]. IgY technology has several advantages over conventional mammalian antibody production: chicken housing is inexpensive, egg collection is noninvasive and IgY isolation is relatively fast and simple [7]. Moreover, due to the phylogenetic distance, conserved mammal proteins are often more immunogenic in birds than in mammals [8]. IgY technology has been evaluated for therapeutic application by oral administration to prevent or control some enteropathogens such as enterotoxigenic Escherichia coli [9], Salmonella Typhimurium [10], S. Enteritidis [11] and rotavirus [12-14].

Extensive applications of $\operatorname{IgY}$ technology demands the optimization of the immunization of hens to produce egg yolk antibodies in a cost-effective manner. There are several immunization protocols that describe up to six immunizations with antigen doses varying from 0.01 to 1 $\mathrm{mg}$ to evoke a strong immune response in order to render high concentrations of specific IgY in the egg yolk [4, 15-18].

The enzyme lumazine synthase from Brucella spp (BLS) has been reported as a carrier for antigen delivery, based on its physicochemical and immunogenic properties [19]. BLS assembles as a remarkably stable dimer of pentamers, with ten N-terminus sites of linkage. Structural analysis of this molecule showed that it is possible to insert peptides and protein domains without disturbing its conformation. It has been reported that BLS possesses 
immunostimulatory properties that enhance both cellular and humoral response [20]. BLS presents immune-enhancing properties only when the foreign antigen is covalently attached to it [20]. Considering its multivalence and immunogenic properties, BLS has been evaluated as a carrier for systemic immunization. Several peptides and a small protein domain of $9 \mathrm{kDa}$ were successfully coupled by recombinant fusion to the structure of BLS. This carrier has also shown to be an efficient adjuvant for oral immunization, eliciting a systemic immune response due to its homodecameric arrangement and remarkable thermodynamic stability [21]. We have previously described the fusion of BLS to the inner domain of the VP8 protein (BLSVP8d) from Bovine Rotavirus (BRV) strain C486. This fusion protein was able to elicit a high antidody response in mice which resulted in fully protection of pups against challenge with virulent $\mathrm{C} 486$ BRV [22]. Rotavirus is the major etiological agent of severe neonatal gastroenteritis in mammalian species, including infants and young children worldwide. It is also responsible for extensive economic losses in animal species. A survey conducted in Argentina during a 10year period, showed that BRV represents the main pathogen associated to neonatal calf diarrhoea in both beef and dairy herds, with $64.5 \%$ overall incidence [23]. Calves are susceptible to rotavirus infection within the first 2 weeks of life and, for this reason, active immunization prior to exposure to virulent strains is almost impossible to accomplish. However, it is well known that the continuous presence of high titers of passive RV antibodies in the gut lumen (either naturally produced or artificially added to the milk) fully protects against diarrhea and significantly reduces virus shedding [24-26]. Passive immunity strategies such as oral administration of specific antibodies from bovine colostrum or chicken egg yolk have been explored and were shown to be effective to prevent RV infections in humans and animals [27-30]. However, IgY-based immunotherapies appear to be more feasible than bovine calostrum-based treatments [30].

The aim of this work was to test BLS as an alternative immunomodulator to improve the antibody response against BRV-VP8d in laying hens in order to maximize the production of specific egg yolk antibodies and to assess their performances in a suckling mouse model.

\section{MATERIALS AND METHODS}

\subsection{Virus and Cells}

The C486 BRV (P[1]G6) strain was propagated in monkey kidney (MA104) cells. Tissue culture supernatants were used in the immunological assays and concentrated as described previously [31], for mouse challenge. MA104 cells were provided by the culture Cell Section of the Institute of Virology, INTA-Castelar. Cells were cultured in complete medium (MEM-D) supplemented with $100 \mathrm{U} / \mathrm{ml}$ penicillin, $100 \mu \mathrm{g} / \mathrm{ml}$ streptomycin and $10 \%$ heat inactivated FBS.

\subsection{Expression and Purification of Recombinant Proteins}

The vectors pET-BLSVP8d (which contains VP8d, the 62 - 224 region of the VP8 protein, downstream BLS gene) and pET-VP8d (which contains only VP8d sequence) were previously generated. Expression and purification of the recombinant proteins have also been reported [22]. Briefly, BLSVP8d and VP8d were expressed as inclusion bodies. The inclusion bodies were solubilised by overnight incubation in a $8 \mathrm{M}$ urea, $50 \mathrm{mM}$ Tris/ $\mathrm{HCl}$, $5 \mathrm{mM}$ EDTA, pH 8 buffer, at room temperature with agitation. The solubilised proteins were purified by anion exchange chromatography in a Q-Sepharose (Pharmacia) column under denaturing conditions; elution was performed using a linear gradient between 0 and $1 \mathrm{M}$ $\mathrm{NaCl}$ in $8 \mathrm{M}$ urea. The purified proteins were refolded by dialysis against a $50 \mathrm{mM}$ Tris/ $\mathrm{HCl}, 150 \mathrm{mM} \mathrm{NaCl}, 5 \mathrm{mM}$ EDTA, $1 \mathrm{mM}$ DTT and $1 \mathrm{mM}$ PMSF, pH 7.4 buffer, at $4^{\circ} \mathrm{C}$. The peaks enriched with BLSVP8d and VP8d were further purified by gel filtration on a Superose 6 (Pharmacia) and Superdex 75 (Pharmacia) columns, respectively. For BLSVP8d, a third purification step on a Superdex 200 column was performed. The purity of the preparations was determined by SDS-PAGE $(12 \%, \mathrm{w} / \mathrm{v})$ and quantified by measuring at $280 \mathrm{~nm}$ wavelength. The purified proteins were dialysed against PBS, frozen in liquid $\mathrm{N} 2$ and stored at $-80^{\circ} \mathrm{C}$.

\subsection{Immunisations of Chickens}

Groups of light brown laying hens $(\mathrm{n}=2)$ seronegatives for RV, were immunized with 1) BLSVP8d (fusion protein), 2) VP8d and 3) mixture of BLS and VP8 (BLS + VP8d). Each group was immunized with $2 \mu \mathrm{g}$ of VP8d. The doses of BLS and BLSVP8d were corrected by their molecular weights to inoculate equimolar amounts of each protein compared to that of VP8d $(0.105 \mathrm{nmol})$.

Hens were immunized with three doses of $0.5 \mathrm{ml}$. Vaccines were prepared with Freund's incomplete adjuvant containing the appropriate antigen in a proportion adjuvant:antigen of 50:50. Inoculations were performed by the intramuscular route at days 0,30 and 75 . Side effects in the site of injection and laying capacity were checked.

Eggs were collected on days 0, 21, 30, 45, 52, 60, 75 and 96 post-first immunization (DPI).

\subsection{Purification of Egg Yolk IgY}

IgY from egg yolk was purified according Akita and 
Nakai (1990). Briefly, the yolks were diluted with 5 volumes of distilled water and then frozen at $-20^{\circ} \mathrm{C}$. Thereafter, diluted yolks were thawed at $4^{\circ} \mathrm{C}$ ON and centrifuged at $8000 \mathrm{~g}$, at $4^{\circ} \mathrm{C}$ for $12 \mathrm{~min}$. The pellet was discarded and $0.24 \mathrm{~g} / \mathrm{ml}$ of $\left(\mathrm{NH}_{4}\right)_{2} \mathrm{SO}_{4}$ were added to the supernatant, incubated for $30 \mathrm{~min}$ at room temperature with slightly stirring and then centrifuged at $10,000 \mathrm{~g}$, $4^{\circ} \mathrm{C}, 12 \mathrm{~min}$. The pellet was resuspended in $\left(\mathrm{NH}_{4}\right)_{2} \mathrm{SO}_{4} 2$ $\mathrm{M}$, for $30 \mathrm{~min}$ at room temperature and centrifuged as above. Finally, the supernatant was discarded, the pellet was resuspended in PBS and then the solution was dialised $\mathrm{ON}$ against $\mathrm{PBS}$ at $4^{\circ} \mathrm{C}$. Concentration of purified IgY was measured by NanoDrop (ND1000, Thermo Scientific).

\subsection{SDS-PAGE and Western Blot (WB)}

Purified IgY were electrophorezed on SDS-PAGE (12\%) and stained with Coomassie blue.

To test the specificity of the purified IgY anti-BLSVP8d, an indirect WB was performed. BLSVP8d and VP8d extracts were subjected to SDS-PAGE (15\%), blotted onto an Immobilon P membrane (Millipore) and blocked ON with PBS Tween 0.1\% (PBS-T) and skim milk 3\%. All subsequent steps were carried out using this buffer. The membrane was then incubated $1 \mathrm{~h}$ at $37^{\circ} \mathrm{C}$ with the purified IgY solution, washed three times and finally incubated $1 \mathrm{~h}$ at $37^{\circ} \mathrm{C}$ with HRP-labeled goat antichicken $\operatorname{IgY}\left(\operatorname{Sigma}^{\circledR}\right)$ for $1 \mathrm{~h}$ at $37^{\circ} \mathrm{C}$. After washing three times, the WB was revealed by $\mathrm{DAB} / \mathrm{H}_{2} \mathrm{O}_{2}$ system $\left(\right.$ Sigma $\left.^{\circledR}\right)$. As negative control a non induced bacteria culture was included.

\subsection{Elisa}

Titers of IgY against VP8d were determined according to Bellido et al. [22]. Briefly, purified VP8d was directly adsorbed onto the plate $(1 \mu \mathrm{g} /$ well $)$ in carbonate-bicarbonate buffer $\mathrm{pH} 9.6$ and blocked with PBS-T, 5\% normal horse serum (blocking buffer) for $1 \mathrm{~h} \mathrm{at} 37^{\circ} \mathrm{C}$. Thereafter, 4-fold dilutions of all IgY samples in blocking buffer were incubated for $1 \mathrm{~h}$ at $37^{\circ} \mathrm{C}$. Plates were washed with PBS-T and incubated with HRP-labeled goat anti-chicken $\operatorname{IgY}\left(\operatorname{Sigma}^{\circledR}\right)$. The reaction was revealed by $\mathrm{ABTS} / \mathrm{H}_{2} \mathrm{O}_{2}$ system and stopped by the addition of 5\% (w/v) SDS. Absorbance was measured at 405 nm (A405) in a Multiskan Ex, Labsystems Inc. The cut off value of the assay was calculated as the mean specific optical density (OD) plus 3 standard deviations from IgY purified samples obtained from 6 unimmunised hens.

As a positive control, a previously purified $\operatorname{IgY}$ against Human RV WA strain, which partially cross-reacts with VP8d C486 BRV, was used.

Titers were expressed as the reciprocal of the highest IgY dilution with an OD value above the cut off.

\subsection{Viral Neutralization (VN) Test}

Virus neutralizing titers were determined by fluorescent focus reduction test as described by To et al. [31] with modifications. Serial diluted samples of the purified $\operatorname{IgY}$ were incubated with $\mathrm{C} 486$ strain $\mathrm{BRV}$ at $37^{\circ} \mathrm{C}$ for $1 \mathrm{~h}$, then they were inoculated onto MA104 cells and further incubated. Fluorescent focus-forming units (FFU) were evaluated by a direct immunofluorescent assay, and neutralization titers were expressed as the reciprocal of the highest dilution showing $>80 \%$ reduction of FFU.

\subsection{RV Protection Assay in Newborn Mice}

Three groups of 10 four-day-old BALB/c mouse pups received $100 \mu \mathrm{l}$ of a solution containing: $0.5 \mathrm{mg}, 0.1 \mathrm{mg}$ or $0.05 \mathrm{mg}$ of IgY anti-BLSVP8d purified from eggs collected from both hens on day 96. Another group of mice received $2.5 \mathrm{mg}$ of IgY anti-WA per pup. This dose was previously demonstrated to have the same neutralizing activity in vitro as $0.5 \mathrm{mg}$ of IgY anti-BLSVP8d.

As negative control a group received $0.5 \mathrm{mg}$ of $\mathrm{IgY}$ purified from unimmunized hens and a placebo group only received sterile PBS. Each treatment was administered by intragastric route using a flexible plastic feeding tube. Treatments were administered once a day for 4 days.

During the second day of the trial and $1 \mathrm{~h}$ after the treatment, pups were orally challenged with $6 \times 10^{5}$ fluorescent focus units (FFUs) (corresponding to $30 \mathrm{di}-$ arrhea doses $50-\mathrm{DD}_{50}$ ) of virulent $\mathrm{C} 486 \mathrm{BRV}$ per mouse. This infective virus dose produced diarrhea in $100 \%$ control naïve animals [22]. Pups were inspected for diarrhea at 24,48 and $72 \mathrm{~h}$ after challenge by gentle palpation of the abdomen [32,33]. After the last inspection, mice were euthanized. The trial was carried out in duplicate in two independent assays.

The Fisher exact test was used to compare the proportions of pups with diarrhoea among the various groups. P values lower than 0.01 were considered significant.

Hens' management, inoculation and sample collection were conducted by trained personnel under the supervision of a veterinarian and in accordance with protocols approved by the INTA's ethical committee of animal welfare $\left(\mathrm{N}^{\circ} 37\right)$.

\section{RESULTS AND DISCUSSION}

Efficiency of the immunization of hens is a key issue that must be addressed to maximize the amount of specific $\mathrm{IgY}$ that can be obtained from the egg yolk.

In this context, novel immunomodulators should be explored, not only to increase the production of antibodies but also to reduce undesirable and painful side effects in the birds due to the inoculation [34]. In this work the 
potential use of the enzyme lumazine synthase (BLS) as an immunomodulator to increase the antibody response in laying hens was tested.

Based on our promising results obtained in mice [22], BLSVP8d fusion protein was selected as antigen, since it was able to induce a strong antibody response using low amounts of protein. In this work immunizations were carried out using $2 \mu \mathrm{g}$ of VP8d, this dose was 100 times lower than the dose used by Kovacs Nolan et al. (2001) to produce IgY against VP8 with high neutralization activeity [15].

In all hens, a single immunization was enough to detect IgY anti-VP8d in the yolks. The presence of IgY after purification was confirmed by SDS-PAGE (Figure 1(a)) and the final concentration of $\mathrm{IgY}$ was $5 \mathrm{mg} / \mathrm{ml}$. The western blot analysis showed that the IgY was able to recognize specifically both the fusion protein BLSVP8d and the monomeric protein VP8d (Figure 1(b)).

The content of specific IgY in the egg extracts was measured by ELISA and VN assay.

According to ELISA, specific IgY were first detected in all groups at day 30 post-immunization (pi). After the first booster, titers of hens immunized with VP8 ranged between 40 and 1000 from days 45 to 60. At day 75, titers declined and after the second booster, levels of antibodies increased to their previous values. Development of the immune response of hens induced by BLS + VP8d was similar to the response of the hens immunized with the monomeric protein alone and titers ranged between 40 and 4000. BLSVP8d evoked a stronger immune response than VP8d or BLS + VP8d. Antibody titers of hens immunized with BLSVP8d ranged between 1000 and 16,000 (Figure 2). Antibody titers of all hens from VP8d and BLS + VP8d groups decreased at least a 4-fold dilution 45 days after the second inoculation. In contrast, antibody levels from one of the two hens immunised with BLSVP8d slightly increased. This finding suggests that the protein fused to BLS is able to maintain a longlasting immune response and, consequently, the number of booster immunizations could be reduced. As expected, after the third immunization, titers of specific antibodies increased and hens immunized with BLSVP8d showed the highest titers (Figure 2).

Although IgY was produced against a single domain of VP8, the VN assay confirmed that anti-VP8d IgY was able to neutralize the activity of C486 BRV. Neutralizing IgY from all groups was first detected on day 45 pi and, from this day onwards, hens immunized with the fusion protein developed the highest neutralization titers: VN titers in VP8d or BLS + VP8d groups ranged between 4 and 64 respectively while titers from BLSVP8d group ranged between 250 and 1000 . The kinetics of the response assayed by VN was similar to the kinetics determined by ELISA (Figure 3).

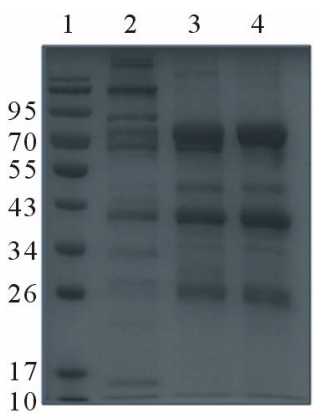

(a)

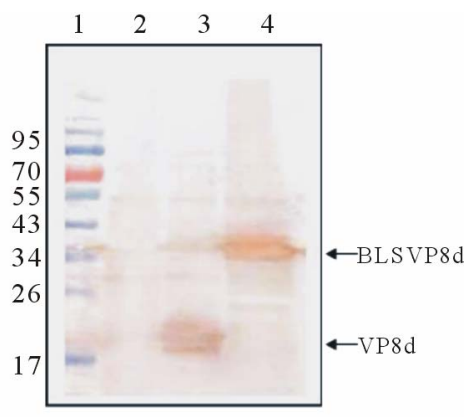

(b)
Figure 1. (a) SDS-PAGE in $12 \%(\mathrm{w} / \mathrm{v})$ polyacrylamide analysis of purified IgY. Lane 1: molecular weight marker (MWM); lane 2: unpurified egg yolk; lane 3: purified BLSVP8d IgY and lane 4: purified C-IgY; (b) Wetern blot analysis of antiBLSVP8d IgY. VP8d and BLSVP8d proteins extracts were run on SDS-PAGE, transferred onto PVDF membrane and probed with anti-BLSVP8d IgY. Lane 1: MM; lane 2: Mock; lane 3: VP8d and lane 4: BLSVP8d.

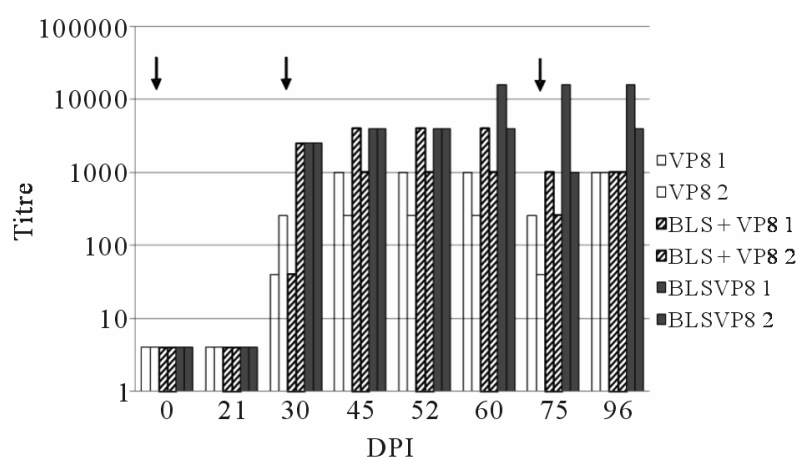

Figure 2. Detection of specific IgY antibodies in egg yolk from immunized hens. Purified IgY response developed by hens immunized with VP8d (empty bars), BLS + VP8d (striped bars) and BLSVP8d (solid bars) was evaluated by ELISA. Titers were expressed as the reciprocal of the highest IgY dilution which gave an OD value above the mean of the OD values of the negative samples plus 3 standard deviations. Arrows in the top of the figure indicate immunization days.

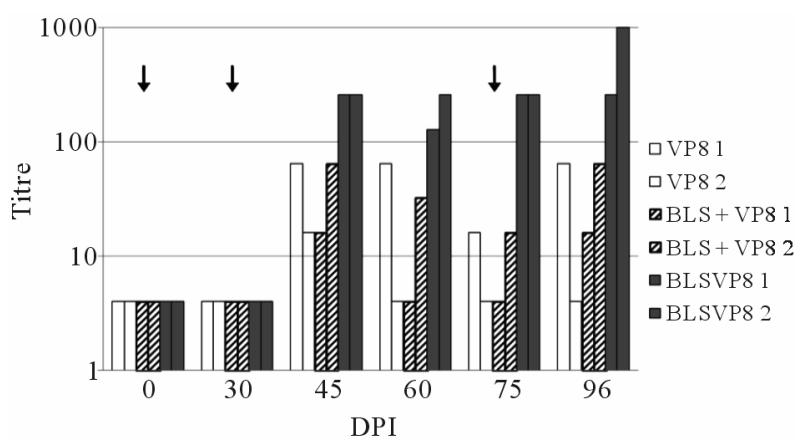

Figure 3. Evaluation of the neutralizing activity of the purified IgY. Neutralization titers of IgY from hens immunized with VP8d (empty bars), BLS + VP8d (striped bars) and BLSVPd (solid bars) are expressed as the reciprocal of the highest dilution showing a $80 \%$ reduction of FFU. Arrows in the top of the figure indicate immunization days. 
Immunogenicity of any antigen could be increased when it is fused to BLS since it can be incorporated at 10 different points due to the polymeric nature of the immunomodulator. This scaffold stimulates the immune system, that has evolved to respond strongly to repetitive and spatially ordered antigens, typically found on microbial surfaces [35,36]. BLS is able to elicit long-lasting humoral and cellular response by several mechanisms. For example, BLS can induce a strong signal transduction mediated by B-cell receptors and it also activates the cellular response by delivering CD8 $+\mathrm{T}$-cell epitopes into the MHC class I pathway. Moreover, BLS also activates and induces the proliferation of dendritic cells via TLR4 $[37,38]$. In this work, hens immunized with BLSVP8d developed high titers of antibodies, even using low amounts of the antigen. This work demonstrates that fusion of VP8d antigen to BLS is able to increase the specific humoral response not only in mammals but also in birds, even if different immunological mechanisms are involved. Indeed, $5 \mu \mathrm{g}$ of $\mathrm{IgY}$ from hens immunized with BLSVP8d were able to block infection of MA-104 cells with bovine rotavirus C486.

Since higher neutralization titers were found in the hens immunized with the fusion protein, these antibodies were further tested in vivo in a mouse model of rotavirus disease. Mice from the groups that received $0.5 \mathrm{mg}$ or $0.1 \mathrm{mg}$ were fully protected $48 \mathrm{~h}$ and $72 \mathrm{~h}$ post-challenge (pc) $(\mathrm{P}=0.0001)$ and the lowest dose assayed, $0.05 \mathrm{mg}$, was able to protect $80 \%$ of the pups 72 hours pc $(\mathrm{P}=$ 0.0086).

In contrast, IgY anti-WA protected $20 \%, 50 \%$ and $70 \%$ of the mice at 24,48 and $72 \mathrm{~h} \mathrm{pc}(\mathrm{P}=0.032)$, respectively. All mice from the placebo group and $80 \%$ of the mice from the control group showed symptoms of diarrhoea (Table 1). Protection rates observed were similar in both trials.

Table 1. RV protection assay in newborn mice.

\begin{tabular}{cccc}
\hline \multirow{2}{*}{ Treatment } & \multicolumn{3}{c}{ Percentage of protection against diarrhea } \\
\cline { 2 - 4 } & $\mathbf{2 4} \mathbf{~ h}$ & $\mathbf{4 8 ~ h}$ & $\mathbf{7 2 ~ h}$ \\
\hline BLSVP8d 0.5 mg & $80 \%$ & $100 \%$ & $100 \%^{\mathrm{a}}$ \\
BLSVP8d 0.1 mg & $40 \%$ & $100 \%$ & $100 \%^{\mathrm{a}}$ \\
BLSVP8d 0.05 mg & $40 \%$ & $40 \%$ & $80 \%^{\mathrm{a}}$ \\
WA 2.5 mg & $20 \%$ & $50 \%$ & $70 \%^{\mathrm{a}}$ \\
C-IgY 0.1 mg & $10 \%$ & $10 \%$ & $20 \%{ }^{\mathrm{b}}$ \\
C-PBS & $0 \%$ & $0 \%$ & $0 \%{ }^{\mathrm{b}}$ \\
\hline
\end{tabular}

Protection rate against diarrhea achieved by purified IgY. Pups were fed with different doses of BLSVP8d IgY, control IgY or PBS and challenged with BRV. The development of diarrhea was monitored daily for up to $72 \mathrm{~h}$ postchallenge. The experiment was performed in two independent assays with ten mice per group. Different letters within columns indicate significant differences.
These results show that IgY-BLSVP8d was able to protect newborn mice from rotavirus disease in a dosedependent and efficient manner. Sarker et al. (2007), also found that a dose of $100 \mu \mathrm{g}$ of IgY produced against human rotavirus was enough to provide high protection levels ( $94 \%$ of protection at 96 hours pc) in the suckling mouse model [13].

This work demonstrates that BLS is a suitable immunomodulator that could be used to produce high levels of egg yolk IgY using low amounts of antigen and few immunizations. Therefore, BLS could be use to obtain IgY against low-immunogenic recombinant proteins and it becomes also appropriate for large-scale production of IgY, thus improving potential applications of IgY technology. Further studies should include the evaluation of the use of BLS combined with other adjuvants specially designed for poultry.

\section{ACKNOWLEDGEMENTS}

We want to thanks Dra Viviana Parreño and her group by their help throughout this work. We also want to thanks CONICET by supporting DB and DG scholarships and to Secretaría de Ciencia y Técnica de La Nación and INTA by supporting this work (PICT 1194).

\section{REFERENCES}

[1] Carlander, D., Kollberg, H., Wejaker, P.E. and Larsson, A. (2000) Peroral immunotherapy with yolk antibodies for the prevention and treatment of enteric infections. Immunologic Research, 21, 1-6. doi:10.1385/IR:21:1:1

[2] Reilly, R.M., Domingo, R. and Sandhu, J. (1997) Oral delivery of antibodies. Future pharmacokinetic trends. Clinical Pharmacokinetics, 32, 313-323. doi:10.2165/00003088-199732040-00004

[3] Svendsen, L., Crowley, A., Ostergaard, L.H., Stodulski, G. and Hau, J. (1995) Development and comparison of purification strategies for chicken antibodies from egg yolk. Laboratory Animal Science, 45, 89-93.

[4] Schade, R., Calzado, E.G., Sarmiento, R., Chacana, P.A., Porankiewicz-Asplund, J. and Terzolo, H.R. (2005) Chicken egg yolk antibodies (IgY-technology): A review of progress in production and use in research and human and veterinary medicine. Altern Lab Anim, 33, 129-154.

[5] Schade R.C.P. (2011) Egg yolk compounds-Livetin fractions. In: Huopalahti, R., Anton, R.L.-F. M. and Schade, R., Eds., Bioactive Egg Compounds, Springer, Berlin, 298.

[6] Schade, R.H.P. and Hlnak, A. (1997) Animal alternatives, welfare and ethics. Elsevier Science Pub Co., New York.

[7] Akita, E.M. and Nakai, S. (1993) Comparison of four purification methods for the production of immunoglobulins from eggs laid by hens immunized with an enterotoxigenic E. coli strain. Journal of immunological methods, 160, 207-214. doi:10.1016/0022-1759(93)90179-B 
[8] Camenisch, G., Tini, M., Chilov, D., Kvietikova, I., Srinivas, V., Caro, J., Spielmann, P., Wenger, R.H. and Gassmann, M. (1999) General applicability of chicken egg yolk antibodies: The performance of IgY immunoglobulins raised against the hypoxia-inducible factor 1alpha. FASEB Journal, 13, 81-88.

[9] Ikemori, Y., Kuroki, M., Peralta, R.C., Yokoyama, H. and Kodama, Y. (1992) Protection of neonatal calves against fatal enteric colibacillosis by administration of egg yolk powder from hens immunized with K99-piliated enterotoxigenic Escherichia coli. American journal of veterinary research, 53, 2005-2008.

[10] Yokoyama, H., Umeda, K., Peralta, R.C., Hashi, T., Icatlo, F.C.Jr., Kuroki, M., Ikemori, Y. and Kodama, Y. (1998) Oral passive immunization against experimental salmonellosis in mice using chicken egg yolk antibodies specific for Salmonella enteritidis and S. typhimurium. Vaccine, 16, 388-393. doi:10.1016/S0264-410X(97)80916-4

[11] Lee, E.N., Sunwoo, H.H., Menninen, K. and Sim, J.S. (2002) In vitro studies of chicken egg yolk antibody (IgY) against Salmonella enteritidis and Salmonella typhimurium. Poultry Science, 81, 632-641.

[12] Kuroki, M., Ohta, M., Ikemori, Y., Peralta, R.C., Yokoyama, H. and Kodama, Y. (1994) Passive protection against bovine rotavirus in calves by specific immunoglobulins from chicken egg yolk. Archives of Virology, 138, 143-148. doi:10.1007/BF01310045

[13] Sarker, S.A., Pant, N., Juneja, L.R. and Hammarstrom, L. (2007) Successful treatment of rotavirus-induced diarrhoea in suckling mice with egg yolk immunoglobulin. Journal of Health, Population, and Nutrition, 25, 465-468.

[14] Hatta, H., Tsuda, K., Akachi, S., Kim, M., Yamamoto, T. and Ebina, T. (1993) Oral passive immunization effect of anti-human rotavirus IgY and its behavior against proteolytic enzymes. Bioscience, Biotechnology, and Biochemistry, 57, 1077-1081. doi:10.1271/bbb.57.1077

[15] Kovacs-Nolan, J., Sasaki, E., Yoo, D. and Mine, Y. (2001) Cloning and expression of human rotavirus spike protein, VP8*, in Escherichia coli. Biochemical and Biophysical Research Communications, 282, 1183-1188. doi:10.1006/bbrc.2001.4717

[16] Larsson, A.C.D. and Wilhelmssonb, M. (1998) Antibody response in laying hens with small amounts of antigen. Food and Agricultural Immunology, 10, 29-36. doi:10.1080/09540109809354966

[17] Liou, J.F., Chang, C.W., Tailiu, J.J., Yu, C.K., Lei, H.Y., Chen, L.R. and Tai, C. (2010) Passive protection effect of chicken egg yolk immunoglobulins on enterovirus 71 infected mice. Vaccine, 28, 8189-8196. doi:10.1016/j.vaccine.2010.09.089 PMid:20937321

[18] Lee, S.B., Mine, Y. and Stevenson, R.M. (2000) Effects of hen egg yolk immunoglobulin in passive protection of rainbow trout against Yersinia ruckeri. Journal of agricultural and food chemistry, 48, 110-115. doi:10.1021/jf9906073

[19] Zylberman, V., Craig, P.O., Klinke, S., Braden, B.C., Cauerhff, A. and Goldbaum, F.A. (2004) High order quaternary arrangement confers increased structural stability to Brucella sp. lumazine synthase. The Journal of biological chemistry, 279, 8093-8101.

doi:10.1074/jbc.M312035200

[20] Craig, P.O., Berguer, P.M., Ainciart, N., Zylberman, V., Thomas, M.G., Martinez Tosar, L.J., Bulloj, A., Boccaccio, G.L. and Goldbaum, F.A. (2005) Multiple display of a protein domain on a bacterial polymeric scaffold. Proteins, 61, 1089-1100. doi:10.1002/prot.20635

[21] Rosas, G., Fragoso, G., Ainciart, N., Esquivel-Guadarrama, F., Santana, A., Bobes, R.J., Ramirez-Pliego, O., Toledo, A., Cruz-Revilla, C., Meneses, G., Berguer, P., Goldbaum, F.A. and Sciutto, E. (2006) Brucella spp. lumazine synthase: A novel adjuvant and antigen delivery system to effectively induce oral immunity. Microbes and Infection/Institut Pasteur, 8, 1277-1286.

[22] Bellido, D., Craig, P.O., Mozgovoj, M.V., Gonzalez, D.D., Wigdorovitz, A., Goldbaum, F.A. and Dus Santos, M.J. (2009) Brucella spp. lumazine synthase as a bovine rotavirus antigen delivery system. Vaccine, 27, 136-145. doi:10.1016/j.vaccine.2008.10.018

[23] Garaicoechea, L., Bok, K., Jones, L.R., Combessies, G., Odeon, A., Fernandez, F., Parreno, V. (2006) Molecular characterization of bovine rotavirus circulating in beef and dairy herds in Argentina during a 10-year period (1994-2003). Veterinary Microbiology, 118, 1-11. doi:10.1016/j.vetmic.2006.06.004

[24] Fernandez, F.M., Conner, M.E., Hodgins, D.C., Parwani, A.V., Nielsen, P.R., Crawford, S.E., Estes, M.K. and Saif, L.J. (1998) Passive immunity to bovine rotavirus in newborn calves fed colostrum supplements from cows immunized with recombinant SA11 rotavirus core-like particle (CLP) or virus-like particle (VLP) vaccines. Vaccine, 16, 507-516. doi:10.1016/S0264-410X(97)80004-7

[25] Saif, L.J., Redman, D.R., Smith, K.L. and Theil, K.W. (1983) Passive immunity to bovine rotavirus in newborn calves fed colostrum supplements from immunized or nonimmunized cows. Infection and Immunity, 41, 1118-1131.

[26] Saif, L.J., Weilnau, P., Miller, K. and Stitzlein, L. (1987) Isotypes of intestinal and systemic antibodies in colostrum-fed and colostrum-deprived calves challenged with rotavirus. Advances in Experimental Medicine and Biology, 216B, 1815-1823.

[27] Erhard, M.H., Gobel, E., Lewan, B., Losch, U. and Stangassinger, M. (1997) Systemic availability of bovine immunoglobulin $\mathrm{G}$ and chicken immunoglobulin $\mathrm{Y}$ after feeding colostrum and whole egg powder to newborn calves. Archiv fur Tierernahrung, 50, 369-380. doi:10.1080/17450399709386146

[28] Kuroki, M., Ikemori, Y., Yokoyama, H., Peralta, R.C., Icatlo, F.C.Jr. and Kodama, Y. (1993) Passive protection against bovine rotavirus-induced diarrhea in murine model by specific immunoglobulins from chicken egg yolk. Veterinary Microbiology, 37, 135-146. doi:10.1016/0378-1135(93)90188-D

[29] Kuroki, M., Ohta, M., Ikemori, Y., Icatlo, F.C.Jr., Kobayashi, C., Yokoyama, H. and Kodama, Y. (1997) Field evaluation of chicken egg yolk immunoglobulins specific for bovine rotavirus in neonatal calves. Archives of virology, 142, 843-851. 


\section{doi:10.1007/s007050050123}

[30] Sarker, S.A., Casswall, T.H., Juneja, L.R., Hoq, E., Hossain, I., Fuchs, G.J. and Hammarstrom, L. (2001) Randomized, placebo-controlled, clinical trial of hyperimmunized chicken egg yolk immunoglobulin in children with rotavirus diarrhea. Journal of Pediatric Gastroenterology and Nutrition, 32, 19-25. doi:10.1097/00005176-200101000-00009

[31] To, T.L., Ward, L.A., Yuan, L. and Saif, L.J. (1998) Serum and intestinal isotype antibody responses and correlates of protective immunity to human rotavirus in a gnotobiotic pig model of disease. The Journal of General Virology, 79, 2661-2672.

[32] Ijaz, M.K., Sabara, M.I., Frenchick, P.J. and Babiuk, L.A. (1987) Effect of different routes of immunization with bovine rotavirus on lactogenic antibody response in mice. Antiviral Research, 8, 283-297. doi:10.1016/S0166-3542(87)80006-2

[33] Lee, J., Babiuk, L.A., Harland, R., Gibbons, E., Elazhary, Y. and Yoo, D. (1995) Immunological response to recombinant VP8* subunit protein of bovine roravirus in pregnant cattle. The Journal of General Virology, 76, 2477-2483. doi:10.1099/0022-1317-76-10-2477
[34] Hendriksen, C. (2006) Replacement, reduction and refinement in the production and quality control of immunobiologicals. AATEX, 11, 155-161.

[35] Bachmann, M.F. and Zinkernagel, R.M. (1996) The influence of virus structure on antibody responses and virus serotype formation. Immunology Today, 17, 553-558. doi:10.1016/S0167-5699(96)10066-9

[36] Chackerian, B., Lenz, P., Lowy, D.R. and Schiller, J.T. (2002) Determinants of autoantibody induction by conjugated papillomavirus virus-like particles. Journal of Immunology, 169, 6120-6126.

[37] Berguer, P.M., Mundinano, J., Piazzon, I. and Goldbaum, F.A. (2006) A polymeric bacterial protein activates dendritic cells via TLR4. Journal of Immunology, 176, 23662372.

[38] Velikovsky, C.A., Goldbaum, F.A., Cassataro, J., Estein, S., Bowden, R.A., Bruno, L., Fossati, C.A. and Giambartolomei, G.H. (2003) Brucella lumazine synthase elicits a mixed Th1-Th2 immune response and reduces infection in mice challenged with Brucella abortus 544 independently of the adjuvant formulation used. Infection and Immunity, 71, 5750-5755.

doi:10.1128/IAI.71.10.5750-5755.2003 